https://helda.helsinki.fi

\title{
Sustainabilities in the resourceful North
}

\section{Lempinen, Hanna}

Routledge

2020-10-10

Lempinen , H , Tennberg , M \& Pirnes , S 2020 , Sustainabilities in the resourceful North . in Resources, Social and Cultural Sustainabilities in the Arctic . Routledge Research in Polar Regions, Routledge , London . https://doi.org/10.4324/9780429057366

http://hdl.handle.net/10138/329138

https://doi.org/10.4324/9780429057366

unspecified

acceptedVersion

Downloaded from Helda, University of Helsinki institutional repository.

This is an electronic reprint of the original article.

This reprint may differ from the original in pagination and typographic detail.

Please cite the original version. 


\section{Chapter 1}

Hanna Lempinen, Monica Tennberg and Susanna Pirnes

\section{Introduction}

\section{Sustainabilities in the resourceful North}

\section{A small, remote town in Eastern Finland}

In the midst of complex, interlinked environmental, climatic and environmental changes and their multiple consequences in the Arctic, people and their communities ideally use their resources rationally, strive for economic diversification, have a strong collective identity and support public participation to cope with, adapt to and transform themselves to maintain their sustainability (sustainable local communities see Raco, 2005). An illustrative example of contemporary challenges posed to people and their communities in the European Arctic can be found in Salla, a municipality near the Finnish-Russian border in Eastern Finland. It is a small, remote municipality and, in many ways, it is also in decline, tackling as it is the challenges of high unemployment, declining livelihoods, out-migration and an aging population. These trends raise concerns for the future of the municipality and its ability to provide basic services and infrastructure for its residents. Resources to support for and further develop Salla include its geographical location near the Finnish-Russian border "as a gateway" for transportation and tourism; its surrounding northern, unique wilderness; and some existing, but rather modest infrastructure for tourism compared to many other ski resorts in Finnish Lapland. Tourism is an important livelihood and employer, and almost seems to be the only sector with prospects for future economic development (Tennberg and Lempinen, 2015). 
Salla promotes itself as "a place where nothing happens," yet in early 2010 the small municipality found itself "in the middle of everything:" plans were being made for visa-free travel between the EU and Russia, and new mines were expected to open in the region. Increased mining, in turn, would have given the impetus to a new rail link between Finland and Russia, which was planned to provide a route to as far as the Arctic Ocean and make the municipality a hub for tourism, industrial development and transportation. Many of these plans, however, were put on hold due to the freezing of EU-Russian relations in the aftermath of the war of Ukraine in 2014, and Salla again found itself at a crossroads with regard to its future. Salla's opportunities to make decisions about its own future, resources and economic diversification are limited. Any expectations relating to the future development of the Salla municipality depend heavily on political and economic actors working elsewhere and decisions made elsewhere, far from the community. The municipality, its people and their livelihoods are therefore highly vulnerable to external changes and disturbances (Tennberg and Lempinen, 2015).

The example of Salla leads us to the problematics of social sustainability and its multiple dimensions, whose study continues to pose theoretical and analytical challenges due to the ambiguous nature of the notions both of "the social" and (its) sustainability (Vallance et al, 2011; Murphy, 2012; Boström, 2012; Latour, 2005). These hitherto largely ignored challenges have recently been considered in the field of Arctic studies where the revival of interest in the societal aspects of sustainability is seen in a growing number of multidisciplinary endeavors to grasp and understand the societal facets of Arctic sustainability, its different definitions, challenges and future trajectories (Petrov et al, 2017; Fondahl and Wilson, 2017; Pram Gad and Strandsbjerg, 2018). They have contributed to the emergence of a new interdisciplinary field of study: Arctic sustainability science (Petrov et al, 2017). 
The Arctic and its development has been discussed mostly from the point of view of natural resources and the implications of their extraction for local communities and indigenous peoples. By contrast, Arctic sustainability science has moved away from perceiving the Arctic as a global resource storehouse and toward investigating the complexity of entanglements of resources, local life and social development. This shift in emphasis has been largely motivated by the increasing awareness of the inadequateness of existing indicators to measure societal development, the politicized nature of the concept of sustainable development as well as the pivotal role that human and social sciences can have in conceptualizing and solving Arctic sustainability concerns. Our book is an empirically grounded contribution to these conceptual and theoretical debates and to the discussion focusing on the relationship between resources, development, and social and cultural (un)sustainability. The book and its diverse Euro-Arctic case studies focus on and illustrate different aspects of why the Arctic resource discourses and practices as they exist today are unsustainable, drawing attention to often neglected human, social and cultural aspects of the sustainability debate.

\section{Defining social and cultural sustainability}

The notions of sustainable development and sustainability are neither new nor unexplored. The term "sustainable development" first appeared in a 1980 report of the International Union for Conservation of Nature (IUCN), but the underlying concerns over the carrying capacity of ecosystems in the face of increasing human impacts and stressors had already been present(ed) in many of the foundational works associated with the environmental awakening of the 1960s and 1970s (e.g. Carson, 1962; Meadows et al, 1973). Politically, the concept saw its breakthrough after the publication of the Brundtland report Our common future (WCED, 1987), which defined sustainable development as "development that meets the needs of the present without compromising the ability of future generations to meet their own needs." Sustainable development became the core 
principle of global environmental cooperation in the 1992 United Nations Conference on Environment and Development. It remains one of the main aims in the Arctic cooperation, and has retained its robustness as a policy concept in national and international discourses. Also, the United Nations recently accepted the new 2030 millennium goals for sustainable development (UN sustainable development goals 2015-2030, 2015). However, the notions of sustainability and sustainable development have been increasingly acknowledged also as political: their applications arrange and rearrange the interrelations between different actors and different entities as well as the understanding of a good life today and tomorrow. This makes sustainability " $a$ concept that does something to the way in which politics unfold" (Pram Gad et al, 2017, p. 15; our italics).

Traditionally, sustainable development has been understood as comprising three interconnected and mutually supportive dimensions or pillars: the economic, environmental and the social aspects of development. Of these, the social dimension has broadly been recognized as the most elusive. The social dimension in the sustainability debates and agendas has been characterized as "fluid" or “dismissed altogether" (Boström, 2012, p. 1), and it has widely been acknowledged as "more difficult to analyze, comprehend, define, and incorporate into sustainability projects and planning than the other dimensions of sustainability" (ibid., p. 6). The messy nature of the debates revolving around the social dimensions of sustainability and sustainable development have led to various interpretations of what the concept might entail. Most commonly, the "social" in the sustainable has been approached and constructed in contextual and developmental terms: as concrete development targets and policy goals such as promoting equity, diversity, social cohesion, quality of life, democratic governance and responsibility (Sen, 1999; Murphy, 2012; Partridge, 2013). From this perspective, many signs of socially unsustainable development can be observed both in the broader Arctic region and in terms of our case study on Salla: youth out-migration, aging populations, 
precarious nature of employment and various social problems, including increasing numbers of suicides (Tennberg and Lempinen, 2015).

Meanwhile, other interpretations of social sustainability have highlighted the necessity of procedural aspects and practices in achieving and maintaining sustainability (Vallance et al, 2011; Del Río and Burguillo, 2008; Vanclay, 2002, 2003). In this, the perceptions and impressions of the individuals and communities affected in one way or another by ongoing development play a role, as does their ability to influence this development. For local people and decision-makers, being able to participate in and influence the development of their region is an important resource as well as a prerequisite for sustainability. Furthermore, communities are not homogenous: even members of the same community can feel very differently about ongoing developments, be unevenly impacted by them and have very different understandings of what social and cultural sustainability or sustainable development might mean (Nuttall, 2010, p. 197; Slootweeg et al, 2001, p. 25; Vanclay, 2003, p. 7). Also in our example case of Salla, the local residents voiced diverse views, expectations, concerns and hopes regarding the municipality's future. For example, while some unreservedly saw increasing tourism as the developmental strategy for the municipality, others expressed concerns about the impacts that its dominance would have for the prospects of other livelihoods and professionals in the area. Coping with disagreements and conflicts inside a community is also an important aspect of social and cultural sustainability (Tennberg and Lempinen, 2015).

In the discussions on the social aspects of sustainability, culture and related issues have traditionally been implicitly included under the broader umbrella of social sustainability (see e.g. Del Río and Burguillo, 2008; Psaridikou and Szerszynski, 2012; Hiedanpää et al, 2012). However, recent years have witnessed an emerging strand of literature highlighting the necessity of understanding culture as a separate — although as a closely enmeshed and intertwined — dimension of sustainability. 
Among these contributions, cultural sustainability has been defined in terms of cultural heritage, as the vitality of local communities and societies, and as cultural changes required to achieve sustainability (Soini and Birkeland, 2014); but attention has also been devoted to what exactly constitutes the "culture" that should be sustained. While no universally applicable definition of what culture entails is neither possible nor desirable, in its broadest terms culture can be understood as the diversity of ways living, being and making sense of the world (see e.g. Mercer, 2002; Wilk, 2002; Dessein et al, 2015, p. 31). In this respect, there is not only one "Salla" in our example case but many of them: a diversity of village life and identities in the villages surrounding the municipal center. Despite youth out-migration and an aging population, there is a strong sense of identity and commitment to continuity of common life (Tennberg and Lempinen, 2015).

\section{Our contribution to the Arctic sustainability debate}

In this book, we take a focus on the social and cultural dimensions of sustainability in the circumpolar North. More specifically, we explore these thematics through paying attention to resources - in different definitions and forms — and the ways in which they entangle in the realities and expectations of social and cultural sustainability in the case-study context of the Arctic region. In doing this, we distance ourselves from the conventional understanding of resources as quantifiable and unquestionable states of the world that can be extracted and harvested and that can be assigned a monetary value that would somehow be accurate, objective and calculable (Lähde, 2016, pp. 60-62; Ferry, 2016). Instead, the chapters of this book approach the question of resources from two separate but interlinked perspectives. On the one hand, (natural) resources and their value and importance are understood as socially and culturally constructed and thus inviting discussion on "how they are constructed, by whom and for whom" (Nilsson and Filimonova, 2013, p. 3; also Bridge, 2009). On the other hand, in other chapters a conscious effort is made to shift the focus of 
inquiry away from natural resources that so often dominate resource-related sustainability debates in the context of the Arctic region, to addressing issues of social, human and cultural capabilities and the roles they have in making and shaping the landscapes of Arctic sustainability (see also Nuttall, 2002). Together, this volume and its case studies contribute to a broadened understanding of the interplay of natural and material resources and social and cultural capabilities as well as their discursive framings. As such, the book takes a fresh look at what a "resource" might entail and problematizes the often simplistically applied notion by drawing attention to their ambiguity, unpredictability and imperfection. The contributions of this book will thus advance the understandings of complex relations and dynamics between resources, peoples and development in the North beyond the mainstream studies of Arctic governance and sustainability science. Our findings and observations about these entanglements are relevant not only in the regional context, but contribute to discussions and debates on the contradicting and conflicting dynamics of sustainable development in an increasingly globalized world.

Another aspect of the sustainability debate that we wish to draw attention to and explicate has to do with the crucial differences between (the notions of) sustainable development and sustainability, more often than not used interchangeably despite the marked differences in their fundamental meanings. Whereas sustainable development implies either development that does not undermine the basis of its own continuity or, alternatively, development toward a state of sustainability, sustainability refers to a state of being or a way of living which can, at least in principle, be maintained indefinitely (Kassel, 2012, p. 34; Missimer et al, 2010, p. 1108). The notion of sustainability thus refers to "ongoing support of life as we know it" (Kassel, 2012, p. 34), that is, maintaining a steady state instead of "developing" or "growing." There is, as critique points out, a mismatch between sustainable development and sustainability. Sustainable development, embracing the idea of continuous growth, even if considered inclusive, equitable and participatory, can still be 
fundamentally opposed to sustainability in the true sense of the word: creating and maintaining conditions that could be continued into the future without destroying the social and ecological foundations they are built on. In this respect, our volume is a bold critique of the contemporary Arctic sustainability science that aims to apolitically reconcile the oftentimes irreconcilable dimensions of economic, environmental and social "development." Through this emphasis, we draw attention to the culturally bound and value-laden nature of the very notion of sustainability itself. Its underlying assumptions about the nature of the societies and the environment, what constitutes as "development" and how best to achieve it are thoroughly culturally mediated. Not only the cultural patterns of acting and thinking that are causing the challenges of sustainability in contemporary societies, but also the solutions and means for addressing them are inherently and unavoidably penetrated by culture (WCED, 1987; Dessein et al, 2015, pp. 29-31). The question arises: are our cultures thinking about and implementing sustainability unsustainably?

Alongside the focus on the interplay of resources and sustainability—and specifically its social and cultural aspects and articulations - the approach of this book underlines the urgent need to address sustainability as the interdisciplinary and multidisciplinary issue that it is. The authors of this volume, all members of the Northern political economy research group at the Arctic Centre, University of Lapland, Finland, investigate and explore social and cultural sustainability in the context of Euro-Arctic case studies through the lenses of and often also combining the perspectives of a wide range of different human and social sciences; equally anthropology, regional science, economics, gender studies and political sciences are represented on the pages of this book. This emphasis on true interdisciplinarity responds to the calls made within the field of Arctic sustainability science (see Petrov et al, 2017) and in broader social sustainability literature that seek an understanding of the "social" that would not be understood as separate from but as embedded in 
the other, equally artificial aspects, pillars or dimensions of sustainability (see e.g. Lempinen, 2018, pp. 55-56).

\section{Structure of the book}

This volume is divided into two sections, Part 1 that takes a broad focus on entanglements of resources and sustainabilities, and Part 2 that takes the question of knowledge in relation to sustainability as its core. In the first part, the discussion is opened by Marjo Lindroth, whose article critically assesses the entanglement of resource extraction and the pursuit of independence in Greenland. As Greenland continues to be economically dependent on the (former) colonizer Denmark, reaching economic self-sufficiency has become a critical political aim. Both the extraction of resources and independence hold out the promise of a better future, one with increased wealth and equality among nations. This entwinement also creates fears about the potential negative social, environmental and cultural impacts of resource extraction. Lindroth argues that affective elements have a significant role in the debates for Greenland's future. By engaging in a discussion of affective elements that are engendered by these visions for the future, the chapter holds that while Greenland's resources and independence already have a material presence, they remain elusive. Affective elements, as the article points out, have a powerful role in contemporary politics in facilitating or preventing certain types of developments.

Hannah Strauss-Mazzullo, whose contribution is based on a case study in Northern Finland, discusses the social acceptance of a new nuclear power plant and a waste storage. The communities in question, Pyhäjoki and (in the southwest of Finland) Eurajoki, generally support the plans while the protest is scattered and met with local opposition. The social acceptance of these projects relies on an entanglement/intertwinement of local and national discursive practices. Locally, the plant 
provides for employment and revenues, and nationally, the plant advances independence from Russian electricity imports and meeting obligations for mitigation of greenhouse gases. While the economic benefits of the nuclear power plant and storage appear short-term and tangible, the problems related to nuclear power and waste, such as accidents and catastrophes, are mostly ignored. The successful handling of high-risk nuclear technology since the 1970 s continues to be an issue of national pride.

In the following article, Joonas Vola concentrates on the potential future development of the Arctic Kemijoki River as a resource in Finnish Lapland. The debate about the river and its use produces an entanglement of regional development, flood risk and economic potentialities of the river. In this discourse, the river could be utilized further for hydropower and to improve the local and regional socio-economic development, while without such development a major risk for the infrastructure and inhabitants of the city of Rovaniemi may realize. The current state of the river is described as socially unsustainable due to the waste of its potential as a resource and because of the threat of flooding it causes for the community. The proposed measures in flood protection management for both gaining economic benefits and preventing floods crucially compromise the ecological sustainability and the life of the river, and narrows down the societal development to a certain predestined path.

In her chapter, Hanna Lempinen focuses on Arctic energy resources through a case study on the hitherto largely unexplored question of how the regional energy concern has been conceptualized from and for the Arctic region. While the Arctic and its energy reserves tend to be predominantly understood in terms of oil and gas exports for international markets, Lempinen examines how the largely underrepresented and grossly understudied social dimension of sustainability is entangled with the regional energy concern. The article also draws attention to the changing yet weighty role 
that is being envisioned for Arctic energy resources in the rapidly warming and gradually decarbonizing (energy) world.

Next, Paula Tulppo discusses the importance of different resources for social and cultural sustainability in the context of Tornio Valley, an area for EU's cross-border cooperation between Finland and Sweden. The chapter analyzes what resources, entangled or not, for regional development can be identified in the documents of the EU's cross-border cooperation program (Interreg V A Nord, 2014-2020) and those drawn up by the Finnish municipalities in the region. The textual analysis of the EU and municipal documents shows similarities in the environmental, economic, cultural and social resources, but the emphasis by the two actors is different. The resources identified in the municipal strategies relate more closely to a good everyday life while the resources in the EU documents focus clearly more on the economic aspects.

In the final chapter of the first part, Adrian Braun discusses innovations in climate policies and their funding. The European Arctic is in a process of transition due to the increasing impacts of climate change and corresponding mitigation and adaptation strategies. The "socially responsible investments" (SRIs) are a potential financial instrument to raise capital to support mitigation of emissions and adaptation measures to climate change. SRIs seek to consider both financial return and the well-being of the society; the aim at a positive social (or environmental) impact needs to be addressed for an investment to be eligible as an SRI. These "green" investments provide opportunities for various actors, such as municipalities, cities and corporations to contribute to the well-being and societal development in the region. Investments into sustainable infrastructures, green housing and circular economy projects may provide pathways to long-term achievements that strive for social and environmental sustainability, but still remain a modestly used opportunity in the European Arctic. While being a fairly novel investment concept in the Arctic context, SRIs 
already have a strong presence on the big financial markets (e.g. New York, Luxembourg, London), and it is interesting how the Nordic markets in Europe follow up on this development in the next few years.

The second part of the volume, exploring the entanglements/intertwinements between different forms of knowledge, producers, holders and users of knowledge, is opened by Gemma Holt. Her chapter focuses on the intersecting roles of knowledge and social values in the scientific assessment of adaptation options to changing environmental conditions from the perspective of political ecology. Her aim is to demonstrate how environmental issues and a changing political landscape have helped shift the meanings and practices of science. The chapter discusses the determination of whose knowledge is relevant for adaptation, how knowledge can be effectively communicated and how it can be linked to policy and practice. The chapter is based on an analysis of the Arctic Council's project Adaptation actions for a changing Arctic (AACA), in particular the Barents area report as a case study, to assess how multiple knowledges are used and serve as a basis for theorizing about the politics of adaptation.

In the next chapter, Monica Tennberg investigates social dimensions of Arctic expertise in Finnish Lapland. Arctic expertise has become a popular approach in European "smart" regional development based on the idea of region-specific skills, competences and knowledge that may lead into new innovations, products and services. Arctic expertise builds on a competent, mobile and healthy workforce, but also on high levels of training, education and investments in research and development as well as networks and partnerships of expertise. The question is whether there can be expertise without experts. While the importance of social sustainability for Arctic expertise has been acknowledged in early Finnish debates, more recently, its social aspects, such as regional innovation potential and creative talent, are not included in the current projects on Arctic expertise. 
This is in a clear contrast to the neighboring countries, Northern Norway and Sweden, and to their understandings on the development of Arctic expertise.

Heidi Sinevaara-Niskanen notes in her chapter that there is a rather recent shift in the focus in Arctic research and politics toward human development and social sustainability. People of the Arctic have been increasingly recognized as the resource of the region in addition to natural resources. However, as the chapter argues, questions of social sustainability and, in particular, questions of gender have been largely sidetracked from these discussions. This is despite the growing significance that gender plays in Arctic developments, including patterns of migration and demographic changes. Sinevaara-Niskanen sheds light on the connections between gender, equality and sustainability in the Arctic by analyzing social scientific Arctic research and documents produced under the auspices of the Arctic Council. The chapter reveals that although there is a growing knowledge of gender issues in the Arctic and recognition of the ways in which gender and sustainability mesh, this knowledge has not substantially altered the perceptions of "Arctic resources."

In the following chapter, Francis Joy studies the misuse of religious traditions, cultural heritage and traditional knowledge of the Sámi within the Finnish tourism industry. The appropriation of Sámi traditions is widespread in Finland because the Sámi have not had the resources or powers to protect their heritage. Consequently, Sámi shamanism, which is a central practice within traditional Sámi religion, has been adapted in various ways to meet the needs of the tourism industry. Moreover, replica drums and other fake Sámi artifacts, including pretend Gákti costume and other designs, are manufactured and distributed by the tourism industry. The legislation as of 2003 , which was meant to protect Sámi cultural heritage, is ambiguous, as are guidelines within the tourism industry. There 
is no effective legal protection in place against copying and exploitation of Sámi cultural heritage in Finland.

Susanna Pirnes discusses the role of history in the social imaginaries of the Russian Arctic. Victorious history is often utilized to amplify the chosen political path, which is very true in any Arctic state. In Russia, polar exploration and the Arctic have been an important part of national history and a source for many heroic stories, which were used during the Soviet era for political purposes. Historical knowledge of people is an instrument through which it is possible for the political elites to use certain fragments of history as a culturally sustainable resource. The question of historical knowledge about the Arctic is deliberated with the concepts of historical culture identity politics.

The concluding chapter by Monica Tennberg, Hanna Lempinen and Susanna Pirnes draws together the main points and lessons from current debates about social and cultural (un)sustainability in the Arctic from the perspective of social imaginaries. Social imaginaries are essential for understanding complex entanglements of resources and sustainabilities, being as they are the very

ways people imagine their social existence, how they fit together with others, how things go on between them and their fellows, the expectations that are normally met, and the deeper normative notions and images that underlie these expectations (Taylor, 2004, p. 23).

\section{References}


Boström, M. (2012) “A missing pillar? Challenges in theorizing and practicing social sustainability: an introduction to the special issue," Sustainability: Science, Practice \& Policy, 8(1), pp. 3-14.

Bridge, G. (2009) “Material worlds: natural resources, resource geography and the material Economy," Geography Compass, 3(3), pp. 1217-1244.

Carson, R. (1962) Silent spring. New York: Houghton Mifflin.

Del Río, P. and Burguillo, M. (2008) “Assessing the impact of renewable energy deployment on local sustainability: towards a theoretical framework," Renewable and Sustainable Energy Reviews, 12, pp. $1325-1344$.

Dessein, J., Soini, K. Fairclough, G. and Horlings, L. (eds.) (2015) Culture in, for and as sustainable development: conclusions from the COST Action IS1007 investigating cultural sustainability. Jyväskylä: Jyväskylä University Press.

Ferry, E. (2016) "Gold prices as material-social actors: the case of the London gold fix," The Extractive Industries and Society, 3, pp. 82-85.

Fondahl, G. and Wilson, G. (eds.) (2017) Northern sustainabilities: understanding and addressing change in the circumpolar world. Cham: Springer.

Hiedanpää, J., Jokinen, A. and Jokinen, P. (2012) "Making sense of the social: human-nonhuman constellations and the wicked road to sustainability," Sustainability: Science, Practice \& Policy, 8(1), pp. 40-49. 
IUCN, International Union for Conservation of the Nature (1980) World conservation strategy: living resource conservation for sustainable development [Online]. IUCN-UNEP-WWF. Available at: https://portals.iucn.org/library/efiles/documents/WCS-004.pdf (Accessed: April 18, 2019).

Kassel, K. (2012) "The circle of inclusion: sustainability, CSR and the values that drive them," Journal of Human Values, 18(2), pp. 133-146.

Latour, B. (2005) Reassembling the social: an introduction to actor-network-theory. Oxford: Oxford University Press.

Lähde, V. (2015) "Politics in a world of scarcity” in Bergnäs, K., Eskelinen, T., Perkiö, J. and Warlenius, R. (eds.) The politics of ecosocialism: transforming welfare. London: Routledge, pp. $55-67$.

Lempinen, H. (2017) The elusive social: remapping the soci(et)al in the Arctic energyscape. Rovaniemi: Lapland University Press.

Meadows, D., Meadows, G., Randers, J., and Behrens, W. III. (1972) The limits to growth. New York: Universe Books.

Mercer, C. (2002) Towards cultural citizenship: tools for cultural policy and development. Stockholm: The Bank of Sweden Tercentenary Foundation \& Gidlunds förlag. 
Missimer, M., Robèrt, K. Broman, G. and Sverdrup, H. (2010) “Exploring the possibility of a systematic and generic approach to social sustainability," Journal of Cleaner Production, 18, pp. 1107-1112.

Murphy, K. (2012) “The social pillar of sustainable development: a literature review and framework for policy analysis," Sustainability: Science, Practice \& Policy, 8(1), pp. 15-29.

Nilsson, A. and Filimonova, N. (2013) Russian interests in oil and gas resources in the Barents Sea. Stockholm Environment Institute Working Paper 2013:5. Stockholm: Stockholm Environment Institute.

Nuttall, M. (2002) “Global interdependence and Arctic voices: capacity-building for sustainable livelihoods," Polar Record, 38(206), pp. 194-202.

Nuttall, M. (2010) Pipeline dreams: people, environment and the Arctic energy frontier. Copenhagen: IWGIA.

Partridge, E. (2014) "Social sustainability," in Michalos, A. (ed.) Encyclopedia of quality of life and well-being research. Dordrecht: Springer, pp. 6178-6186.

Petrov, A., BurnSilver, S., Stuart Chapin III, F., Fondahl, G., Graybill, J., Keil, K., Nilsson, A., Riedlsperger, R. and Schweitzer, P. (2017) Arctic sustainability research: past, present and future. London: Routledge. 
Pram Gad, U., Jakobsen, U. and Strandsbjerg, J. (2017) "Politics of sustainability in the Arctic: a research agenda" in Fondahl, G. and Wilson, G. (eds.) Northern sustainabilities: understanding and addressing change in the circumpolar world. Cham: Springer, pp. 13-23.

Pram Gad, U. and Strandsbjerg, J. (eds.) (2018) The politics of sustainability in the Arctic: reconfiguring identity, time, and space. London: Routledge.

Psaridikou, K. and Szerszynski, B. (2012) “Growing the social: alternative agrofood networks and social sustainability in the urban ethical foodscape," Sustainability: Science, Practice and Policy, 8(1), pp. 30-39.

Raco, M. (2005) "Sustainable development, rolled-out neoliberalism and sustainable communities," Antipode, 37(2), pp. 324-347.

Sen, A.K. (1999) Development as freedom. New York: Anchor Books.

Slootweeg, R., Vanclay, F. and van Schooten, M. (2001) "Function evaluation as framework for the integration of social and environmental impact assessment," Impact Assessment and Project Appraisal, 19(1), pp. 19-28.

Soini, K. \& Birkeland, I. (2014) "Exploring the scientific discourse on cultural sustainability," Geoforum, 51, pp. 213-223.

Taylor, C. (2004) Modern social imaginaries. London: Duke University Press. 
Tennberg, M. and Lempinen, H. (2015) “Sosiaalista kestävyyttä etsimässä: tapaustutkimuksena Salla," Kosmopolis, 45(3), pp. 27-43.

UN sustainable development goals 2015-2030 (2015) Available at:

http://www.un.org/sustainabledevelopment/sustainable-development-goals/. (Accessed: April 18, 2019).

Vallance, S., Perkins, H.C. and Dixon, J.E. (2011) "What is social sustainability? A clarification of concepts," Geoforum, 42, pp. 342-348.

Vanclay, F. (2002) “Conceptualising social impacts,” Environmental Impact Assessment Review, 22, pp. 183-211.

Vanclay, F. (2003) “International principles for social impact assessment," Impact Assessment and Project Appraisal, 21(1), pp. 5-11.

WCED (1987) Report of the World Commission on Environment and Development: our common future. Oxford: Oxford University Press.

Wilk, R.R. (2002) “Culture and energy consumption” in Bent, R., Baker, R. and Orr, L. (eds.) Energy: science, policy, and the pursuit of sustainability. Washington DC: Island Press, pp. 109130. 